\title{
Simulating the Operation of a Port Contender With SIM 4: Applying Monte Carlo Techniques to the Gandalf PACX IV
}

Lawrence F. Tolendino

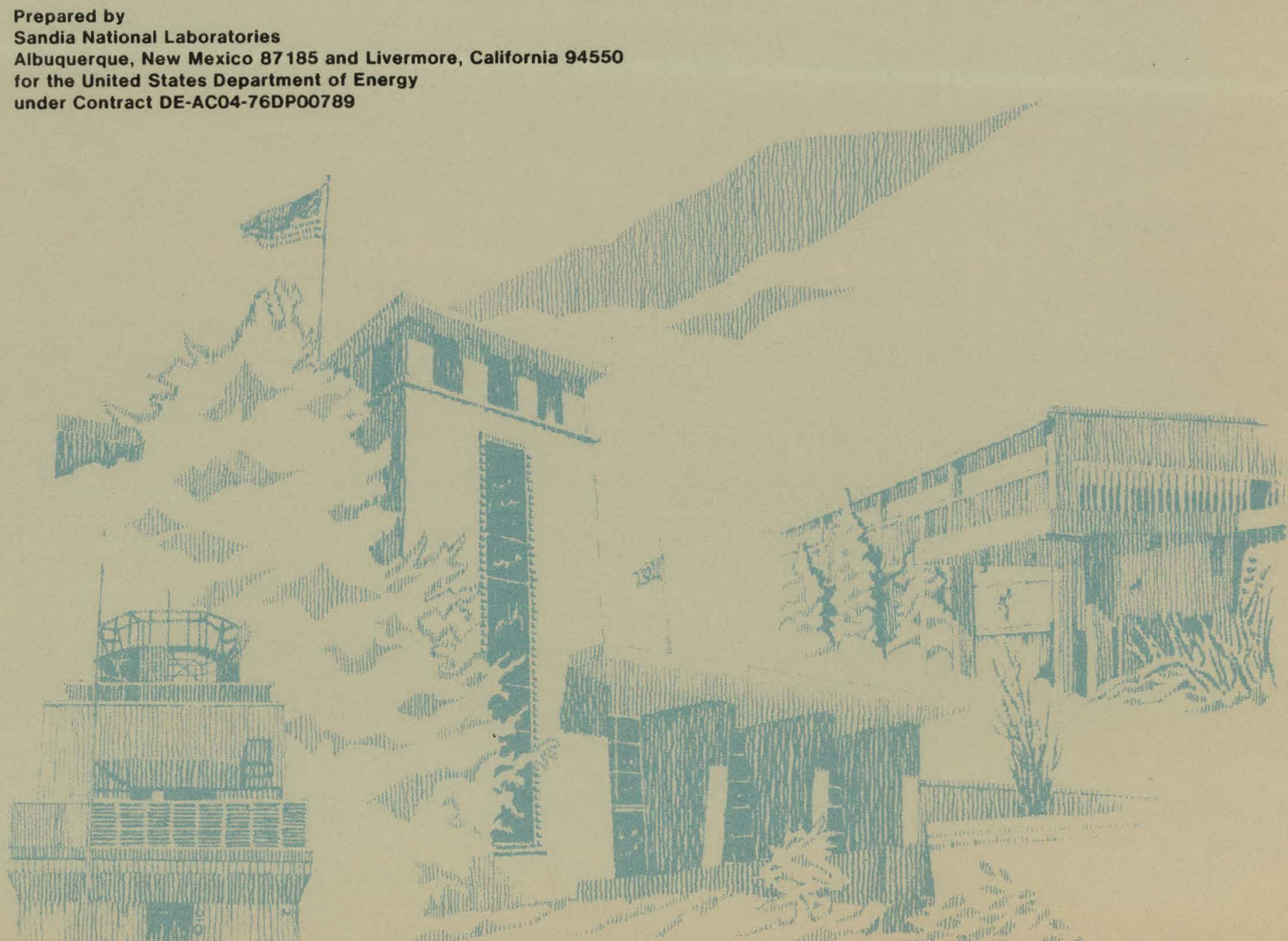

\section{Sandia National Laboratories}

f the United States Department of Energy

Contract DE-AC04-76DP00789 


\section{DISCLAIMER}

This report was prepared as an account of work sponsored by an agency of the United States Government. Neither the United States Government nor any agency Thereof, nor any of their employees, makes any warranty, express or implied, or assumes any legal liability or responsibility for the accuracy, completeness, or usefulness of any information, apparatus, product, or process disclosed, or represents that its use would not infringe privately owned rights. Reference herein to any specific commercial product, process, or service by trade name, trademark, manufacturer, or otherwise does not necessarily constitute or imply its endorsement, recommendation, or favoring by the United States Government or any agency thereof. The views and opinions of authors expressed herein do not necessarily state or reflect those of the United States Government or any agency thereof. 


\section{DISCLAIMER}

Portions of this document may be illegible in electronic image products. Images are produced from the best available original document. 
Issued by Sandia National Laboratories, operated for the United States Department of Energy by Sandia Corporation.

NOTICI: This report was prepared as an account of work sponsored by an agency of the United States Government. Neither the United States Government nor any agency thereof, nor any of their employees, nor any of their contractors, subcontractors, or their employees, makes any warranty, express or implied, or assumes any legal liability or responsibility for the accuracy, completeness, or usefulness of any information, apparatus, product, or process disclosed, or represents that its use would not infringe privately owned rights. Reference herein to any specific commercial product, process, or service by trade name, trademark, manufacturer, or otherwise, does not service by trade nuter ity necessarily con Ttates Gover its endorement, recomen by the United States Government, any agency thereof or any of thei contractors or subcontractors. The views and opinions expressed herein d not necessarily state or reflect those of the United States Government, any agency thereof or any of their contractors or subcontractors.

Printed in the United States of America Available from

National Technical Information Service

U.S. Department of Commerce

5285 Port Royal Road

Springfield, VA 22161

NTIS price codes

Microfiche copy: A01 


\section{PAGES 1 to 2 WERE INTENTIONALLY LEFT BLANK}




\section{SAND82-0162}

Unlimited Release

Printed March 1982

SIMULATING THE OPERATION OF A PORT CONTENDER WITH SIM 4: APPLYING MONTE CARLO TECHNIQUES TO THE GANDALF PACX IV

by

L. Tolendino

Division 2648

Computer Communications Design Division

Sandia National Laboratories

Albuquerque, NM 87185

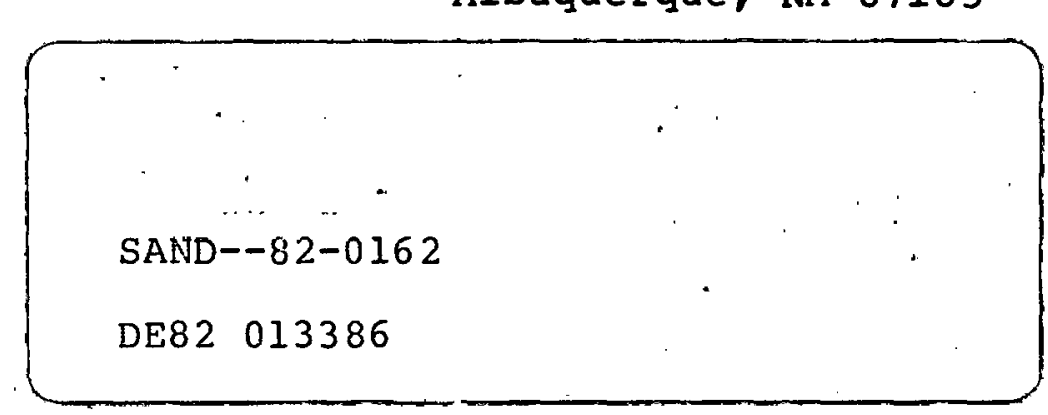

ABSTRACT

A simulation program, SIM 4, has been written which utilizes usage statistics to project PACX IV performance.. Using this program, system managers can allocate scarce resources in an efficient manner. 
This page intentionally left blank 
Table of contents

I. Introduction $\quad 1 \quad$ Page

I. Introduction $\cdot \bullet^{-} \cdot \bullet^{-} \cdot \bullet^{-} \cdot \bullet^{-} \cdot \bullet^{-} \cdot \bullet^{-} \cdot \bullet^{\bullet} \cdot$

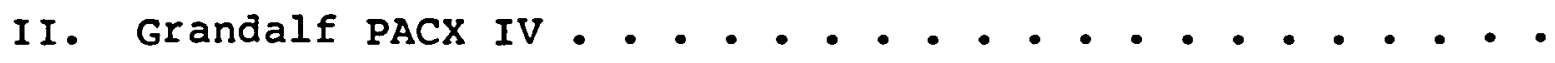

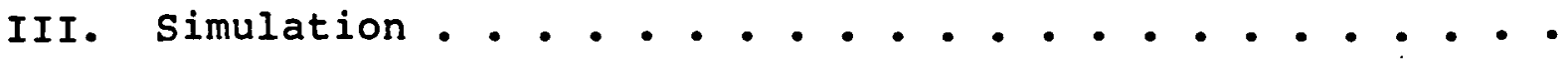

IV. Implementation - . - . - . - . . . . . . . . .

v. conclusion . . . . . . . . . . . . . . . . 
This page intentionally left blank 
I. Introduction

Recently, several Gandalf PACX IV port contenders have been placed in operation at Sandia National Laboratories. These units provide a contention function for the many computer terminals which vie for limited computer ports. In addition, the port contenders allow a terminal to connect to various computer resources. Providing the proper number of computer ports for each resource has been a hit-or-miss affair until recently. computer usage is now recorded, and more scientific techniques can be used to determine computer port allocation.

A software package called MODEL $^{3}$ has been developed which projects computer port allocation based on previous usage. A second package, SIM 4, tests the recommended allocation using Monte Carlo techniques. SIM 4 will simulate the performance of a single class of service on a PACX IV for the requested number of $8 \frac{1}{2}$-hour days. When the simulation run is complete, a report is generated detailing the system's performance.

II. Gandalf PACX IV

The Gandalf PACX IV used at Sandia is a port contender with a capacity of 512 terminals and 256 computer ports. Using TDM techniques, any terminal can be logically connected to any computer port at asynchronous data rates up to 9600 bps. One or more ports are assigned to each computer resource served by a PACX IV, and the connected terminals contend for these ports. If all the ports for a particular class of service are busy, additional terminals which request this service will be queued. As ports become free, terminals are removed from the queue and placed into service. The mode of operation of a PACX IV allows one to use the techniques of queueing theory in the analysis of the PACX IV's performance in a very straightforward way. 
III. Simulation

One class of service is simulated at a time. Actual usage statistics for each class of service are analyzed by a separate software package, MODEL, which predicts the number of computer ports (servers) necessary to provide an acceptable level of service. MODEL also determines the arrival rate of customers, expected service times, and the size of the user population for this class. The simulation program, SIM 4, then uses the arrival rate, service rate, user population, and number of servers to determine the queueing characteristics of this single queue, multiserver, limited population system, $M / M / m .1$

SIM 4 uses synchronous timing and a simple two-step technique to simulate the operation of the Gandalf port contender. 2 synchronous timing means that the system clock is advanced one unit of time followed by a check for any significant events. If a significant event has occurred, the state variables for the system are updated before the clock is allowed to advance another unit of time. System state variables in SIM 4 are the number of users in service and the number of users in the queue. For SIM 4, there are only two events which must be checked. First, has a new user arrived during the period, and, second, if there were any users in service at the beginning of the period, has one completed service. The arrival rate for users and the expected service times are used to deduce the probabilities of these two events occurring. By choosing the interval of time sufficiently small, the probability of two or more arrivals in one time period can be made effectively zero. The possibility of two or more service completions is precluded in the same way. A period of "one second" was used in SIM 4. 
Once the basic time interval for the simulation is chosen, it must be determined if a significant event occurred. For each interval of time, a computer-generated random number, in the range $0-1$, is compared to the probability of a significant event occurring. If the random number is less than the probability of the event, the event is said to have occurred. Next, the state variables for the simulation, the number of users in service and in the queue, are changed to reflect significant events. In this way, the single queue multiserver system is simulated on a second-by-second basis for as many $8 \frac{1}{2}$-hour days as desired. See figure 1. 


\section{Program SIM 4}

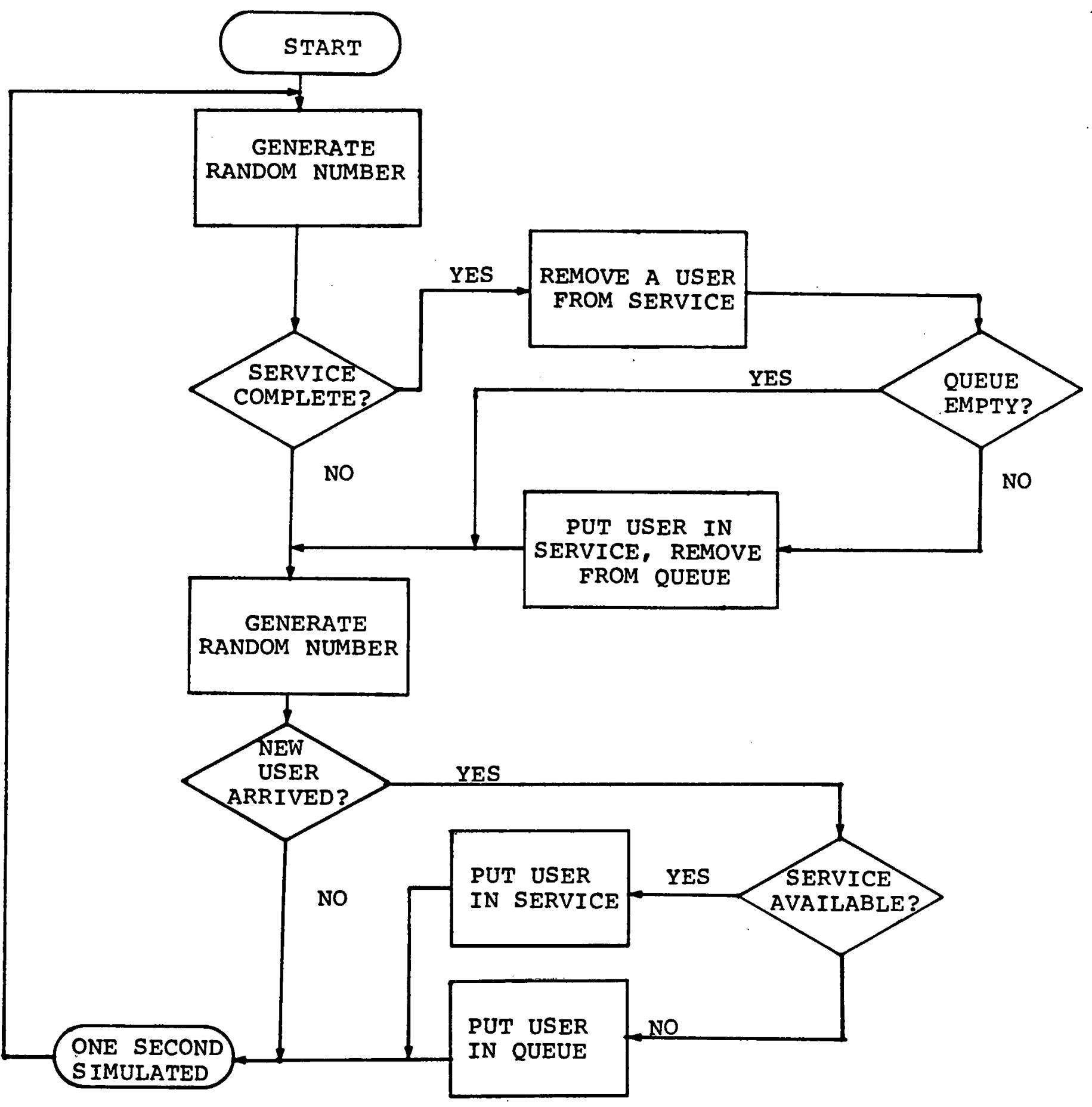

FIGURE 1 
IV. Implementation

The simulation program, SIM 4, was written in FORTRAN IV (FORTRAN 66) to run on a DEC PDP 11/44 minicomputer using the RSXIl-M operating system. For this particular study, the parameters of interest were the probability of obtaining immediate service, the average wait in the queue, and the maximum wait in the queue. These parameters were determined for each of the classes of service on the terminal switching network. In order to simplify matters, each $8 \frac{1}{2}$ hour day was assumed to start from the zero state, no users in the queue or in service. This assumption is warranted by study of actual usage statistics. Also, the possible effects of lunch hour or other cyclic variations in usage were not considered realizing that this produced more conservative results.

SIM 4 uses a data file generated by the modeling program as input.. The data file contains usage statistics averaged over the entire period recorded as well as statistics based on the busiest 30-minute interval in the period. It also contains the recommended number of ports for each class of service based on the average statistics as well as a recommendation based on the busiest 30-minute statistics. When the simulation program is run, the number of days to simulate is chosen by the operator.

In normal operation, the simulation program generates two types of reports which are written to computer disk files. These files are later printed for distribution. The simulation program generates a one-page report for each class of service in the terminal switching notwork (Figure 2). The report details the number of servers assigned by the modeling program and the user population, arrival rate, and expected service time obtained from recorded usage statistics. The report also shows the behavior of the queue for this class of service. 
The simulation, which was run for "l day," shows the behavior of the queue as well as the probability of immediate service, 0.94118 , the expected wait in the queue, 0.065 minutes, and the longest wait in the queue, 2.15 minutes. On four occasions, the queue had length 1 , and on one occasion, the length was 2 . In Figure 2, the report also shows that the modeling program recommends one server for class 4 on port contender 0 . From usage statistics, a user population of 133, an arrival rate of 0.00038 arrivals/minute, and an expected service time of 1.0 minute were recorded.

The second report generated by the simulation program, Figure 3, contains one page for each port contender in the terminal switching network. The report summarizes data generated from usage statistics, recommendations of the modeling program, and results of the simulation program. The report is organized by class of service and shows actual usage statistics in the first three columns. These statistics are the number of computer ports assigned to this class, the number of connects to this class, and the total connect time for this class in minutes. The fourth column shows the number of ports recommended by the modeling program, and the remaining columns show the results of a 1-day simulation for PACX 0 using the recommended number of ports. These results include the probability of no wait, the expected wait, and the longest wait in the queue for each class.

v. Conclusion

Simulation has been shown to be an effective way of verifying a specific port contender configuration. The reports generated by the simulation program provide a concise overview of the operation of the terminal switching network. Taken together with the results of the modeling program, they provide tools for the network managers, which allows them to allocate scarce resources in an equitable way. 
A second program, which is an interactive version of SIM 4, allows one to modify the parameters of the simulation. These modifications demonstrate the sensitivity of the system to various changes. In particular, it is of interest to change the number of servers, computer ports, and observe system performance.

\section{Bibliography}

1. Kleinrock, L., Queueing systems Vol II Computer Applications, (John Wiley and Sons, 1976), p 13.

2. Hillier, F. S. and Lieberman, G. J., Operations Research, (Holden-Day Inc., 1974), Chapter 15.

3. Vahle, M. O., The Allocation of computer ports within a Terminal Switching Network: An Application of Queueing Theory to Gandalf port Contenders, Sandia National Laboratories, Albuquerque, NM, SAND82-0176.

LT: sas : $6396 \mathrm{~A}: 03 / 01 / 82 \mathrm{X}$ 


\section{SIMULATION FOR PACX 0, CLASS 4 , WITH 1 SERVER \\ USER POPULATION, 133}

The arrival rate per terminal was 0.00038 arrivals $/ \mathrm{min}$.

The expected service time per terminal was 1.0 minutes for 1 day of simulation.

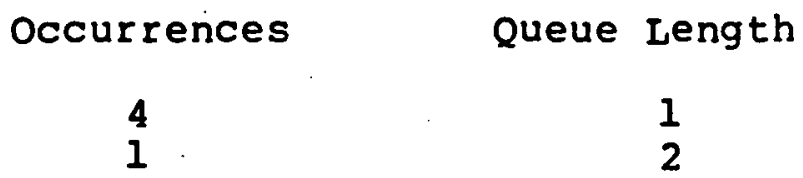

For this run, the probability of immediate service was 0.94118 . The expected wait in the queue was 0.065 minutes.

The longest wait observed was 2.15 minutes.

\section{FIGURE 2}


REPORT FOR PACX 0

DATA INITIALIZED $11 / 23 / 81$

\begin{tabular}{|c|c|c|c|}
\hline CLASS & $\begin{array}{c}\text { CURRENT } \\
\text { PORTS } \\
\end{array}$ & $\begin{array}{c}\text { TOTAL } \\
\text { CONNECTS } \\
\end{array}$ & $\begin{array}{l}\text { TOTAL } \\
\text { TIME }\end{array}$ \\
\hline $\begin{array}{r}0 \\
2 \\
3 \\
4 \\
5 \\
6 \\
15 \\
16 \\
17 \\
21 \\
26 \\
27 \\
31 \\
33 \\
34 \\
35 \\
36 \\
43 \\
44 \\
46 \\
47 \\
62 \\
65 \\
66 \\
71 \\
75 \\
106 \\
110 \\
111 \\
112 \\
115 \\
116 \\
117 \\
160 \\
170 \\
171 \\
172 \\
173 \\
174\end{array}$ & $\begin{array}{r}65 \\
25 \\
1 \\
1 \\
2 \\
1 \\
5 \\
24 \\
23 \\
2 \\
1 \\
1 \\
24 \\
3 \\
9 \\
15 \\
3 \\
2 \\
5 \\
2 \\
1 \\
4 \\
1 \\
1 \\
6 \\
4 \\
1 \\
1 \\
1 \\
1 \\
1 \\
1 \\
1 \\
3 \\
1 \\
1 \\
1 \\
1 \\
1\end{array}$ & $\begin{array}{r}4 \\
2244 \\
218 \\
231 \\
292 \\
130 \\
134 \\
725 \\
1225 \\
47 \\
3 \\
1 \\
2492 \\
258 \\
2082 \\
1712 \\
3 \\
345 \\
1729 \\
13 \\
37 \\
306 \\
20 \\
39 \\
458 \\
497 \\
7 \\
5 \\
18 \\
14 \\
40 \\
20 \\
24 \\
69 \\
2 \\
2 \\
2 \\
2 \\
2 \\
1\end{array}$ & $\begin{array}{r}34 \\
48262 \\
218 \\
241 \\
402 \\
132 \\
5303 \\
31466 \\
37454 \\
2071 \\
7 \\
1 \\
36986 \\
5106 \\
38081 \\
33725 \\
4 \\
2325 \\
7443 \\
408 \\
348 \\
4566 \\
95 \\
1640 \\
6524 \\
7850 \\
21 \\
7 \\
137 \\
95 \\
533 \\
165 \\
1225 \\
2304 \\
51 \\
7 \\
31 \\
35 \\
3\end{array}$ \\
\hline
\end{tabular}

1 DAY SIMULATED

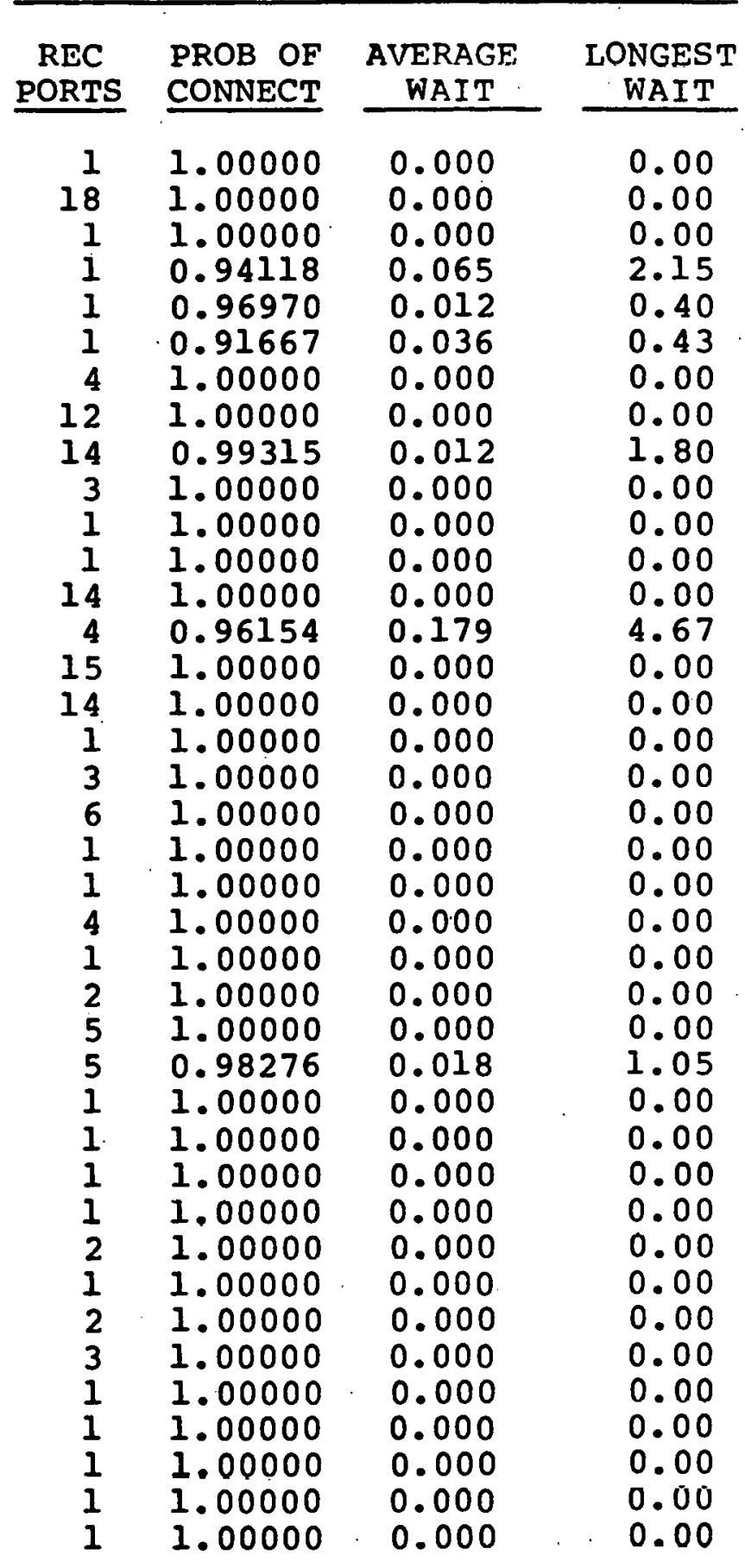

FIGURE 3 


$\begin{array}{ll}\text { Distribution: } \\ 2600 & \text { L. E. Hollingsworth } \\ 2610 & \text { D. C. Jones } \\ 2612 & \text { J. A. Cooper } \\ 2612-1 & \text { R. A. Trudo } \\ 2614 & \text { A. R. Iacoletti } \\ 2620 & \text { R. J. Detry } \\ 2630 & \text { E. K. Montoya } \\ 2635 & \text { P. A. Lemke } \\ 2636 & \text { W. F. Mason } \\ 2640 & \text { J. L. Tischhauser } \\ 2644 & \text { D. M. Darsey } \\ 2645 & \text { L. D. Bertholf } \\ 2646 & \text { M. R. Scott } \\ 2648 & \text { D. H. Schroeder } \\ 2648 & \text { M. D. Thompson } \\ 2648 & \text { L. F. Tolendino (5) } \\ 2648 & \text { M. O. Vahle } \\ 3141 & \text { L. J. Erickson (5) } \\ 3151 & \text { W. L. Garner (3) } \\ & \text { For DoE/TIC } \\ \text { DOE/TIC } & \text { (25) } \\ 8266 & \text { M. Dalin 3l54-3) } \\ \text { M. A. Pound (1) }\end{array}$




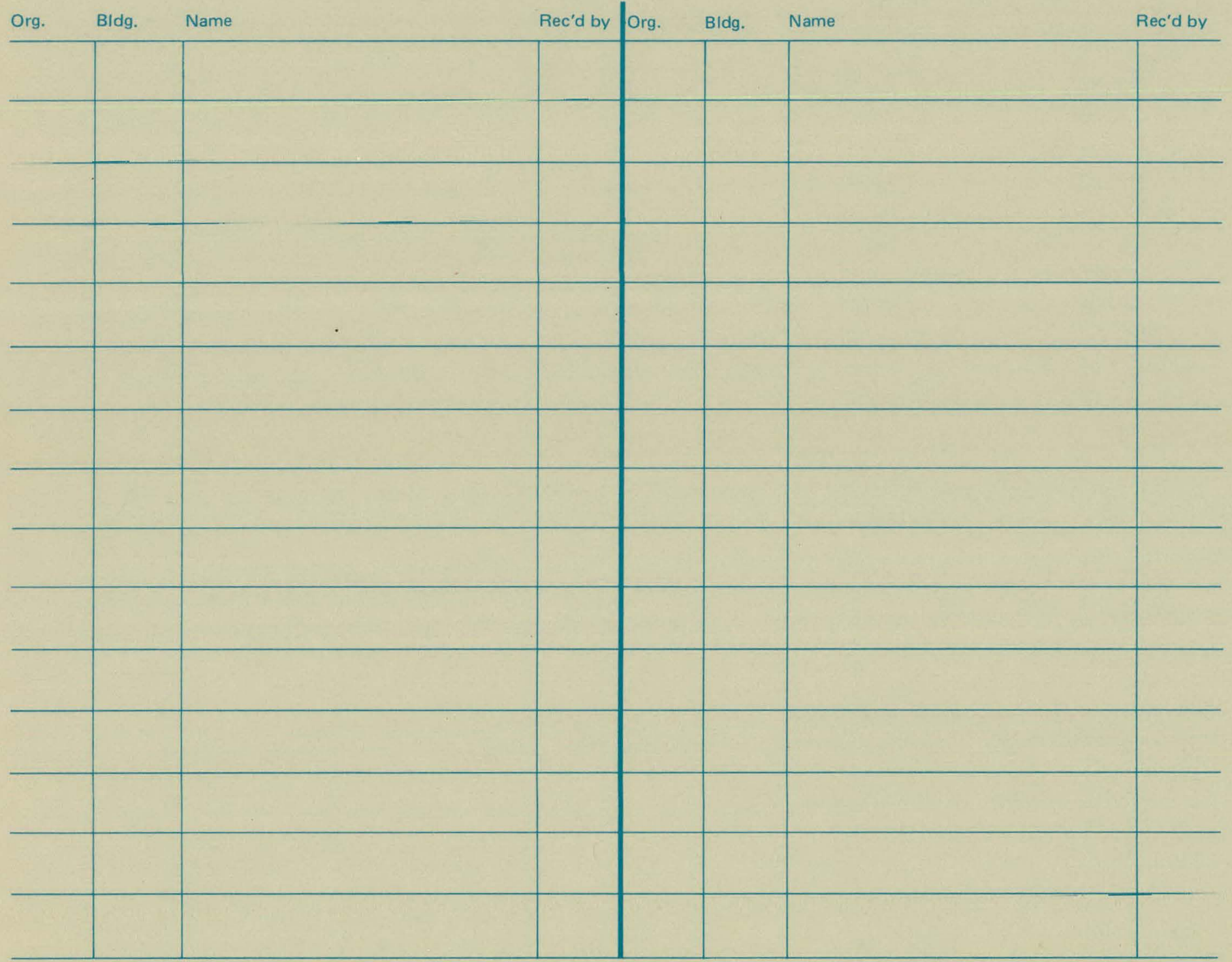

